\title{
A comparison of ground reaction force components according to the foothold heights in 16-t truck during downward step
}

\author{
Seung-Hyun Hyun, Che-Cheong Ryew* \\ Department of Kinesiology, College of Natural Science, Jeju National University, Jeju, Korea
}

The aim of this study is to compare and analyze the components of ground reaction force (GRF) relative to the foothold heights during downward step of 16 -t truck. Adult males $(n=10)$ jumped downward from each 1st, 2nd, 3rd foothold step and driver's seat orderly using hand rail. Sampling rate of force components of 3 axis (medial-lateral [ML] GRF, anterior-posterior [AP] GRF, peak vertical force [PVF]), variables (COPx, COPy, COP area) of center of pressure (COP), loading rate, and stability index (ML, AP, vertical, and dynamic postural stability index [DPSI]) processed from GRF system was cut off at 1,000 Hz. and variables was processed with repeated one-way analysis of variance. AP GRF, PVF and loading rate showed higher value in case of not used hand rail than that used hand rail in all 1st, 2nd, and 3rd of foothold step.
DPSI showed more lowered stability in order of 2nd, 3rd step than 1st foothold step used with hand rail, of which showed lowest stability from driver's seat. COPx, COPy, and COP area showed higher value in case of 2nd and 3rd than that of 1st of foothold step, and showed lowest stability from driver's seat. It is more desirable for cargo truck driver to utilize an available hand rail in order of 3rd, 2nd, and 1st of foothold step than downward stepping directly, thus by which may results in decrease of falling injuries and minimization of impulsive force transferring to muscular-skeletal system.

Keywords: 16-t truck, Ground reaction force, Foothold, Downward step

\section{INTRODUCTION}

Cargo truck is vehicle for small and large scale of carrying capacity, which is manufactured by designs normalized for rough work fields with upgraded excellent competition such as renewing of a mounting capacity, driving efficiency of fuel and design etc. in the midst of overloaded fee soaring of operation and fierce competition in large sized truck market (SCANIA Korea, 2014).

But chronic fatigue of truck driver was cumulated with driving and operation of long range and period of time. Driver's fatigue cumulated for long range can bring about serious problems such as sleeping drive (Williamson et al., 1996) and reduction of capacity keeping up a constant velocity (Brookhuis and de Waard, 1993).

That is, fatigue cumulated during driving may cause reduction counteracting ability in case of unpredictable emergency situation with function deterioration of sensory and information processing capacity (Babkoff et al., 1988; Rosa and Colligan, 1992). Also in addition fatigue, drivers can encounter an excessive danger of low back pain (L5/S1) and urine pain with body vibration (Bovenzi et al., 2006; Seidel, 1993), which showed more urine pain and low back pain in job driver than nonjob driver epidemiological survey and showed 249 out of 489 driver (59\%) (Andrusaitis et al., 2006).

But more important facts is performed down-upward step in a state of inactivated sensory and information processing capability due to long range driving. Most drivers undergo inconvenience of foothold step and risk of falling simultaneously, and have a falling accident with careless stepping. Foothold step was manufactured with numbers of 1st, 2nd, or 3rd for driver's convenience according to cargo height and maximal loading quantity. But standards of 3 rd foothold step may be reduced in vertical height between

\footnotetext{
${ }^{*}$ Corresponding author: Che-Cheong Ryew (ib) https://orcid.org/0000-0001-9473-3990 Department of Kinesiology, College of Natural Science, Jeju National University, 102 Jejudaehak-ro, Jeju 63243, Korea

Tel: +82-64-754-3588, Fax: +82-64-757-1752, E-mail: ryew@jejunu.ac.kr

Received: August 25, 2017 / Accepted: October 30, 2017
}

This is an Open Access article distributed under the terms of the Creative Commons Attribution Non-Commercial License (http://creativecommons.org/licenses/by-nc/4.0/) which permits unrestricted non-commercial use, distribution, and reproduction in any medium, provided the original work is properly cited. 
two step when comparing with 2nd, but stair pattern of foothold step over 4.5 -t truck was manufactured with almost vertical $\left(90^{\circ}\right)$ to the ground.

When compared with structure of building, structure of stair consists of raiser, tread and pitch (Roys, 2001), consecutive two tread or raiser of perpendicular distance between tread plate and landing means horizontal distance from bottom to nosing. If tread, raiser, and incline angle of public stair of building is under $28 \mathrm{~cm}$, under $18 \mathrm{~cm}, 33^{\circ}$, respectively (Perry and Burnfield, 2010), standard and foothold step of truck is too high and inconvenient for up and downward step.

Survey result of stair height in public bus showed 27.00 \pm 1.32 $\mathrm{cm}$ of $1 \mathrm{st}, 26.50 \pm 2.17 \mathrm{~cm}$ of $2 \mathrm{nd}, 37.66 \pm 0.28 \mathrm{~cm}$ of $3 \mathrm{rd}$, showed $3.70 \mathrm{~N} / \mathrm{BW}$ of peak vertical force (PVF) at ground touch-down from 3rd height (Ryew and Hyun, 2013). Particularly If impulsive force occurs at touch down between foot and ground is not absorbed properly, risk of injuries for muscular skeletal system may increase (Nigg et al., 1987), and in fact, case of falling-death during downward from 25-t cargo truck was reported (Kim, 2012).

Table 1. Characteristics of subjects

\begin{tabular}{lr}
\hline Variable & Mean \pm SD \\
\hline Age $(\mathrm{yr})$ & $30.90 \pm 5.85$ \\
Heights $(\mathrm{cm})$ & $178.09 \pm 2.76$ \\
Body mass $(\mathrm{kg})$ & $75.07 \pm 5.41$ \\
Arm length $(\mathrm{cm})$ & $77.09 \pm 2.09$ \\
Leg length $(\mathrm{cm})$ & $100.56 \pm 3.11$ \\
\hline
\end{tabular}

$\mathrm{SD}$, standard deviation.

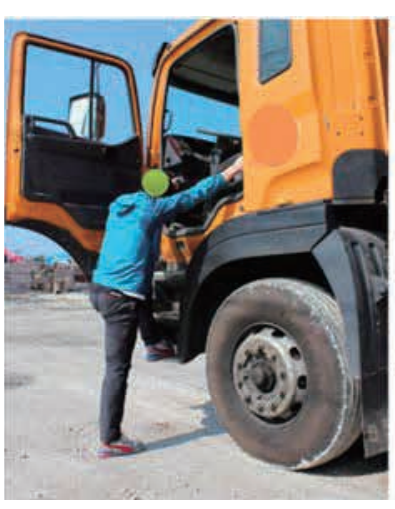

1st Foothold

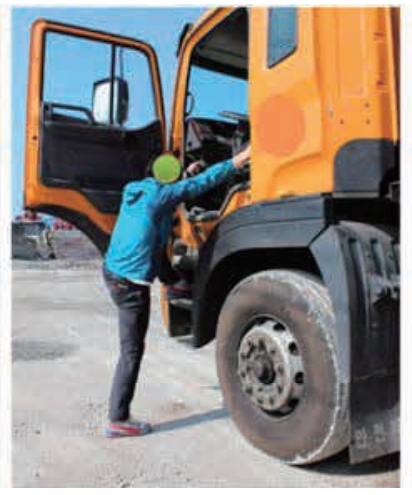

2nd

Foothold

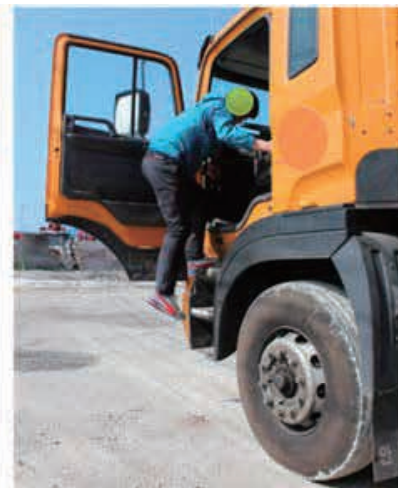

3rd

Foothold

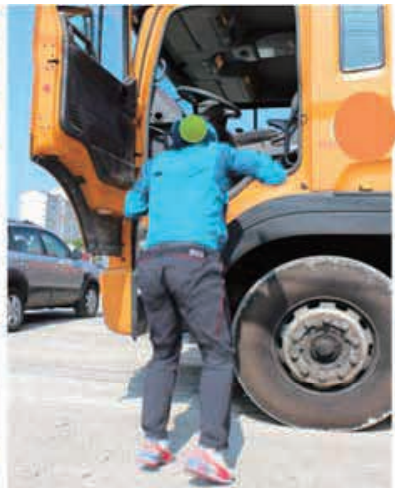

Jumping form driver's seat

Used the exit aids

Fig. 2. Types of descending motions. 
same identity for body height, body weight, length of upper arm (from acromial to midphalanx) and lower leg (from foot plantar to anterior superior iliac spine) of participants.

\section{Experimental procedure}

Wooden box (1 ea) of height level of GRF (AMTI-OR-7, Advanced Mechanical Technology Inc., Watertown, MA, USA) was positioned under truck tire to standardize the height between ground and foothold step of 16-t cargo truck (Fig. 1). Because narrowed landing area and anxiety brings about data error when participants dropped on the force plate (1 ea), researcher set up a similar wooden boxes with GRF standards as Fig. 2.

Difference of Impact type was occurred according to increase of touch-down distance during downward from bus stair (Hyun and Ryew, 2014b), with which intentional movement of lower leg and velocity control of COG may cause data error of GRF (Perry and Burnfield, 2010). Thus researcher recommended participants to select the preferred distance of touch-down and velocity after providing enough rehearsal time during downward step from truck.

\section{Analysis and process of data}

Components of GRF during downward step was analyzed during supporting phase of right foot, and normalized and processed from a point of PVF appearance. Then $\mathrm{N}$ of GRF data was normalized as divided by body weight.

$\Delta \mathrm{COPx}$ and $\Delta \mathrm{COPy}$ of center of pressure (COP) variables was compared with relative $\Delta$ value of displacement of minimum and maximum occurring in direction of medial-lateral (ML) and anterior-posterior $(\mathrm{AP})$ axis, and $\mathrm{COP}$ area was integrated with area occurred by $\Delta$ COPx and $\Delta$ COPy (Hyun and Ryew, 2014a, 2014b).

$$
\mathrm{COP} \text { area }=\int_{\mathrm{t} 1}^{\mathrm{t} 2} \Delta \mathrm{COPx} \cdot \Delta \mathrm{COPy}
$$

Stability index was calculated with value from 3 axis of GRF occurred during jumping and landing Wikstrom et al. (2005), time elapsed of touch down in case of this study according to use of hand rail and individual traits may be delayed. Because of the more delay of landing time, the more improved stability with increase of the number of data sample, dynamic postural stability index (DPSI) was calculated in direction of ML, AP, and vertical (V) to solve the problem.

$$
\begin{array}{cc}
\text { MLSI }=\sqrt{\sum\left(0-\mathrm{Fx}_{\max }\right)^{2} / \text { samples }} & \text { APSI }=\sqrt{\sum\left(0-\mathrm{Fy}_{\max }\right)^{2} / \text { samples }} \\
\text { VSI }=\sqrt{\sum\left(0-\mathrm{Fz}_{\max }\right)^{2} / \text { samples }} & \text { DPSI }=\text { MLSI }+ \text { APSI }+ \text { VSI }
\end{array}
$$

When stability index for variables of MLSI, APSI, VSI, DPSI in each direction showed high value, it means lowered stability, and while in case of low index, it means improved stability.

GRF data was processed with Kwon GRF 2.0 program (Visol, Gwangmyeong, Korea), Excel 2007 (Microsoft, Redmond, WA, USA), and PASW 21.0 (SPSS Inc., Chicago, IL, USA). Computed variables are expressed as a mean \pm standard deviation and repeated measures one-way analysis of variance were performed. Post hoc test (Duncan) was treated in case of showing significant difference at $P<0.05$.

\section{RESULTS}

Components of GRF according to types of downward step did not show significant difference $(P>0.05)$ (Table 2). AP GRF, PVF, and loading rate showed significant difference by types of downward step as of higher value from driver seat than 1st, 2nd, and 3 rd foothold step $(P<0.001)$.

Stability index of MLSI, APSI, VSI, and DPSI by types of downward step showed significant difference $(P<0.001)$ as of higher index from driver seat than 1st, 2nd, and 3rd foothold step (Table 3).

While COPx variables by types of downward step (Table 4 ) did not show significant difference $(P>0.05)$, COPy and COP area

\begin{tabular}{|c|c|c|c|c|c|c|c|}
\hline \multirow{2}{*}{ Variable } & \multicolumn{4}{|c|}{ Descending (D) types } & \multirow{2}{*}{$F$} & \multirow{2}{*}{$P$-value } & \multirow{2}{*}{ Posthoc } \\
\hline & 1st foothold & 2nd foothold & 3rd foothold & Driver's seat & & & \\
\hline ML GRF (N/BW) & $0.04 \pm 0.17$ & $-0.00 \pm 0.18$ & $0.05 \pm 0.27$ & $-0.02 \pm 0.46$ & 0.366 & 0.668 & NS \\
\hline AP GRF (N/BW) & $-0.33 \pm 0.24$ & $-0.55 \pm 0.33$ & $-0.36 \pm 0.39$ & $0.90 \pm 0.50$ & 62.531 & $<0.001^{* * *}$ & $D>1,2,3$ \\
\hline $\mathrm{PVF}(\mathrm{N} / \mathrm{BW})$ & $2.81 \pm 1.10$ & $4.00 \pm 1.30$ & $4.71 \pm 1.20$ & $5.87 \pm 1.91$ & 23.067 & $<0.001^{* * *}$ & $D>2,3>1$ \\
\hline Loading rate (N/BW/sec) & $51.30 \pm 28.88$ & $87.62 \pm 55.80$ & $134.82 \pm 91.80$ & $287.42 \pm 157.54$ & 25.735 & $<0.001^{* * *}$ & $D>3>1$ \\
\hline
\end{tabular}
showed significant difference $(P<0.05)$ as of less value from driv-

Table 2. Change in GRF variables according to the descending types

Values are presented as mean \pm standard deviation.

GRF, ground reaction force; ML, medial-lateral; AP, anterior-posterior; PVF, peak vertical force; NS, not significant.

${ }^{* * *} P<0.001$. 
Table 3. Change in stability index according to the descending types

\begin{tabular}{|c|c|c|c|c|c|c|c|}
\hline \multirow{2}{*}{ Variable } & \multicolumn{4}{|c|}{ Descending (D) types } & \multirow{2}{*}{$F$} & \multirow{2}{*}{$P$-value } & \multirow{2}{*}{ Posthoc } \\
\hline & 1st foothold & 2nd foothold & 3rd foothold & Driver's seat & & & \\
\hline $\mathrm{MLSI}$ & $0.02 \pm 0.02$ & $0.02 \pm 0.01$ & $0.04 \pm 0.01$ & $0.10 \pm 0.05$ & 24.655 & $<0.001^{* * *}$ & $D>1,2,3$ \\
\hline APSI & $0.05 \pm 0.07$ & $0.07 \pm 0.05$ & $0.09 \pm 0.04$ & $0.28 \pm 0.17$ & 23.090 & $<0.001^{* * *}$ & $D>1,2,3$ \\
\hline VSI & $0.38 \pm 0.29$ & $0.47 \pm 0.28$ & $0.83 \pm 0.63$ & $1.44 \pm 0.79$ & 16.491 & $<0.001^{* * *}$ & $D>3>1,2$ \\
\hline DPSI & $0.45 \pm 0.36$ & $0.57 \pm 0.34$ & $0.97 \pm 0.67$ & $1.83 \pm 0.97$ & 20.046 & $<0.001^{* * *}$ & $D>3>1$ \\
\hline
\end{tabular}

Values are presented as mean \pm standard deviation.

MLSI, medial-lateral stability index; APSI, anterior-posterior stability index; VSI, vertical stability index; DPSI, dynamic posture stability index.

${ }^{* * *} P<0.001$.

Table 4. Change in COP variables according to the descending types

\begin{tabular}{|c|c|c|c|c|c|c|c|}
\hline \multirow{2}{*}{ Variable } & \multicolumn{4}{|c|}{ Descending (D) types } & \multirow{2}{*}{$F$} & \multirow{2}{*}{$P$-value } & \multirow{2}{*}{ Posthoc } \\
\hline & 1st foothold & 2nd foothold & 3rd foothold & Driver's seat & & & \\
\hline $\mathrm{COPx}(\mathrm{cm})$ & $1.85 \pm 1.63$ & $1.81 \pm 1.63$ & $2.31 \pm 1.99$ & $2.63 \pm 1.92$ & 0.999 & 0.400 & NS \\
\hline COPy $(\mathrm{cm})$ & $12.81 \pm 7.98$ & $10.11 \pm 3.16$ & $12.27 \pm 10.62$ & $3.12 \pm 3.31$ & 8.069 & $<0.001^{* * *}$ & $D>1,2,3$ \\
\hline COP area $\left(\mathrm{cm}^{2}\right)$ & $22.71 \pm 0.21$ & $19.01 \pm 18.81$ & $33.51 \pm 38.54$ & $8.51 \pm 9.45$ & 17.000 & $0.016^{*}$ & $D>3$ \\
\hline
\end{tabular}

Values are presented as mean \pm standard deviation.

COP, center of pressure; COPx, COP x axis; COPy, COP y axis; NS, not significant.

${ }^{*} P<0.05$. ${ }^{* *} P<0.001$.

er's seat than 1st, 2nd, and 3rd foothold step.

\section{DISCUSSION}

Exposure to whole-body mechanical vibration (vibration) is now widely recognized as associated with musculoskeletal disorders of the spinal system amongst occupational driver (Okunribido et al., 2006), truck driver can be experience musculoskeletal injuries during downward stepping from the driver's seat (Fathallah and Cotnam, 2000). Clear diagnosis and prescription are very important to maximize the effectiveness of exercise rehabilitation depending on the type of injury in truck driver, but quantitative data such as impact type and posture stability are lacking during downward step in cargo truck.

While studies and concerns on risks of an nontraffic accident nontraffic of truck driver was focused on for a long time (Bunn et al., 2008; Fathallah and Cotnam, 2000; Lincoln et al., 2004; Spielholz et al., 2008), quantitative data for preprevention related with falling injuries during downward step from cargo truck is insufficient as usual. Particularly because truck drivers should do downward step frequently when dealing with various parcels on loading board in addition to driving (Shibuya et al., 2010), then heavy impulsive force can be transferred to muscular skeletal system. To investigate the mechanism concretely, this study undertook to analyze components of GRF from 16-t cargo truck manufactured in type of foothold step of 3 stairs.

ML GRF and AP GRF are shearing force acting parallel with foot-ground at touch-down of foot. ML GRF has a widen variability in occurring pattern and value according to individual's trait at touch-down of foot during locomotion (Cavanagh and Lafortune, 1980). This study did not show significant difference of ML GRF, but rather considered to be influenced by a point of time at touchdown, position, and posture of downward step etc. of foot.

While AP GRF did not show significant difference as of negative value (-) among each foothold step of 1 st, 2 nd, and $3 \mathrm{rd}$, and downward step from driver's seat was performed with body's controlling for the backward movement against driver's seat, then corresponded to one times $(0.9 \mathrm{~N} / \mathrm{BW})$ of body weight.

When observed a motion of downward step from driver's seat in sagittal plane, forward rotational force was occurred at touchdown, and it may induce a risk of rolling injuries.

While PVF (N/BW) showed about 2-3.5 times of body weight at mid stance phase during running (Breit and Whalen, 1997; Cavanagh and Lafortune, 1980; Munro et al., 1987), showed 2.81 N/BW of 1st downward step, after increase of 4 times of body weight in 2nd and 3rd and increased to $5.87 \mathrm{~N} / \mathrm{BW}$ of downward step from driver's seat of this study. Also loading rate showed an higher value according to increase of foothold heights as of 287.42 N/BW/sec from driver's seat, which meant transferring to body with heavy impulsive force for short period during downward step. 
Generally high value of GRF increases supporting force of muscle and bone tissue (Breit and Whalen, 1997), thus articular and muscular system under excessive GRF due to transfer of largest external force on body at PVF may cause injuries (Cerulli et al., 2003; Hootman et al., 2007; Miyama and Nosaka, 2004). Therefore it is necessary to wear a shock-absorber of good quality, do enough warm-up for jumping-landing motion during running and sport activities.

Warm-up in sport activities improves flexibility of agonist muscle, range of movement of articular system and prevent injuries of skeletal muscle (Nosaka et al., 2004). Because motion of repeated downward step in case of drivers cargo truck in conditions of fixed sitting posture for a long-time and cumulated fatigue was performed, it was considered to be transferred heavy impulsive force to muscular skeletal system even if in motion of downward step from driver's seat, 2nd or 3rd using hand rail.

Variables of MLSI, APSI, VSI and DPSI showed high value of index in order of 1st, 2nd, 3rd, and driver's seat, but showed lowered stability. Increase of dynamic postural stability index of variables of MLSI, APSI, VSI, and DPSI was considered due to increase of GRF components or occurred result within more less period at touch down.

The higher height of foothold, the higher index according to type of downward step, more, but showed lowered stability. COP area of COP variables showed increase pattern in order of $1 \mathrm{st}$, $2 \mathrm{nd}$, and 3rd and showed lowest value in case of driver's seat. Downward step from driver's seat with higher value of DPSI and heavier impulsive force on body can improve stability by securing of more COP area.

When considering the above, it is necessary for truck driver to evade the downward step from driver's seat, utilize foothold and hand rail in order of 3rd, 2nd, and 1st, which contribute to reduction of falling injuries and minimization of impulsive force on muscular skeletal system for safety and stability for cargo truck driver.

\section{CONFLICT OF INTEREST}

No potential conflict of interest relevant to this article was reported.

\section{ACKNOWLEDGMENTS}

This work was supported by the Ministry of Education of the Republic of Korea and the National Research Foundation of Ko- rea (NRF-2015S1A5B5A07041192).

\section{REFERENCES}

Andrusaitis SF, Oliveira RP, Barros Filho TE. Study of the prevalence and risk factors for low back pain in truck drivers in the state of São Paulo, Brazil. Clinics (Sao Paulo) 2006;61:503-510.

Babkoff H, Mikulincer M, Caspy T, Kempinski D, Sing H. The topology of performance curves during 72 hours of sleep loss: a memory and search task. Q J Exp Psychol A 1988;40:737-756.

Bovenzi M, Rui F, Negro C, Agostin F, Angotzi G, Bianchi S, Bramanti L, Festa G, Gatti S, Pinto L, Rondina L, Stacchini N. An epidemiological study of low back pain in professional drivers. J Sound Vib 2006;289: 514-539.

Breit GA, Whalen RT. Prediction of human gait parameters from temporal measures of foot-ground contact. Med Sci Sports Exerc 1997;29:540547.

Brookhuis KA, de Waard D. The use of psychophysiology to assess driver status. Ergonomics 1993;36:1099-1110.

Bunn TL, Slavova S, Hall L. Narrative text analysis of Kentucky tractor fatality reports. Accid Anal Prev 2008;40:419-425.

Cavanagh PR, Lafortune MA. Ground reaction forces in distance running. J Biomech 1980;13:397-406.

Cerulli G, Benoit DL, Lamontagne M, Caraffa A, Liti A. In vivo anterior cruciate ligament strain behaviour during a rapid deceleration movement: case report. Knee Surg Sports Traumatol Arthrosc 2003;11:307311.

Fathallah FA, Cotnam JP. Maximum forces sustained during various methods of exiting commercial tractors, trailers and trucks. Appl Ergon 2000;31:25-33.

Hootman JM, Dick R, Agel J. Epidemiology of collegiate injuries for 15 sports: summary and recommendations for injury prevention initiatives. J Athl Train 2007;42:311-319.

Hyun SS, Ryew CC. Comparison analysis of ground reaction force patterns according to the stairs heights and bag weights during downward stairs in women. Health Sports Med 2014a;16:41-52.

Hyun SS, Ryew CC. Investigation of the ground reaction force parameters according to the shoe's heel heights and landing distance during downward stairs on bus. Korean J Sport Biomech 2014b;24:151-160.

Kim TE. The Famers Newspaper. Death during descending in cargo truck. The Famers Newspaper. [Internet]. 2012 Jul 11 [cited 2015 May 28]. Available from: https:/www.nongmin.com/news/NEWS/ECO/ FNC/231755/view.

Lincoln AE, Sorock GS, Courtney TK, Wellman HM, Smith GS, Amoroso PJ. Using narrative text and coded data to develop hazard scenarios 
for occupational injury interventions. Inj Prev 2004;10:249-254.

Miyama M, Nosaka K. Influence of surface on muscle damage and soreness induced by consecutive drop jumps. J Strength Cond Res 2004; 18:206-211.

Munro CF, Miller DI, Fuglevand AJ. Ground reaction forces in running: a reexamination. J Biomech 1987;20:147-155.

Nigg BM, Bahlsen HA, Luethi SM, Stokes S. The influence of running velocity and midsole hardness on external impact forces in heel-toe running. J Biomech 1987;20:951-959.

Nosaka K, Sakamoto K, Newton M, Sacco P. Influence of pre-exercise muscle temperature on responses to eccentric exercise. J Athl Train 2004;39:132-137.

Okunribido OO, Magnusson M, Pope MH. Low back pain drivers: the relative role of whole-body vibration, posture and manual materials handling. J Sound Vib 2006;298:540-555.

Perry J, Burnfield JM. Gait analysis: normal and pathological function. Thorofare (NJ): Slack; 2010.

Rosa RR, Colligan MJ. Application of a portable test battery in the assessment of fatigue in laboratory and worksite studies of 12-hour shifts. Scand J Work Environ Health 1992;18 Suppl 2:113-115.

Roys MS. Serious stair injuries can be prevented by improved stair de- sign. Appl Ergon 2001;32:135-139.

Ryew CC, Hyun SS. The kinetic comparison analysis of gait posture on the bus downward stair according to shoe's heel and stair heights in the women. Korean J Phys Edu 2013;52:523-536.

SCANIA Korea [Internet]. Seoul: SCANIA Korea; 2014 [cited 2015 May 20]. Available from: https://www.scania.com/kr/ko/home.html.

Seidel H. Selected health risks caused by long-term, whole-body vibration. Am J Ind Med 1993;23:589-604.

Shibuya H, Cleal B, Kines P. Hazard scenarios of truck drivers' occupational accidents on and around trucks during loading and unloading. Accid Anal Prev 2010;42:19-29.

Spielholz P, Cullen J, Smith C, Howard N, Silverstein B, Bonauto D. Assessment of perceived injury risks and priorities among truck drivers and trucking companies in Washington State. J Safety Res 2008;39:569576.

Wikstrom EA, Tillman MD, Smith AN, Borsa PA. A new force-plate technology measure of dynamic postural stability: the dynamic postural stability index. J Athl Train 2005;40:305-309.

Williamson AM, Feyer AM, Friswell R. The impact of work practices on fatigue in long distance truck drivers. Accid Anal Prev 1996;28:709-719. 